\title{
Educational Poverty in the Italian Context
}

\author{
Antonella Nuzzaci \\ Department of Human Studies, University of L'Aquila, L'Aquila, Italy \\ Email: antonella.nuzzaci@univaq.it
}

How to cite this paper: Nuzzaci, A. (2021). Educational Poverty in the Italian Context. Open Journal of Social Sciences, 9, 103-119. https://doi.org/10.4236/jss.2021.91008

Received: December 11, 2020

Accepted: January 15, 2021

Published: January 18, 2021

Copyright () 2021 by author(s) and Scientific Research Publishing Inc. This work is licensed under the Creative Commons Attribution International License (CC BY 4.0).

http://creativecommons.org/licenses/by/4.0/

\begin{abstract}
Starting from a multidimensional approach to the concept of educational poverty, the objective of this contribution is to offer an overview of the effects of the COVID-19 pandemic emergency on poverty levels in Italy. It is based on the analysis of data linked to economic poverty in the Italian context, taking into account social, educational, cultural, educational and extra-scholastic factors in an attempt to initiate as complete an analysis as possible of the phenomenon and its transformations as a result of the health emergency.
\end{abstract}

\section{Keywords}

Educational Poverty, COVID-19, Italy, Inequalities

\section{Between Structural Poverty and Educational Poverty}

Poverty studies often discourage those who carry them out because of the many difficulties they face when dealing with this phenomenon, both in terms of the strict clarification of the concept and the conditions to which it refers and in terms of its measurability (Nuzzaci et al., 2020). Although there is extensive literature on poverty measurement (Ravallion, 1998; Ravallion \& Bedani, 1994) has not yet reached unanimous agreement on its definition and the methodological and conceptual issues relating to it. On many sides and from different perspectives, poverty has gradually been studied and specified at different levels to clarify its components and dimensions (Alkire \& Foster, 2011a, 2011b, 2016) and refine dimensions (its meanings, also in reference to the best known distinction between "relative poverty" and "absolute poverty" and the declination of educational poverty (see Figure 1). International organizations such as the United Nations (United Nations, 2015) and the World Bank (2018) have adopted standardized criteria to define thresholds separating poverty from non-poverty, seeking to go beyond the absence of income to also involve everything related to restrictions on access to a wide range of resources (education, health, rights, etc.) (Sen, 
1986). The use of the poverty line leads, however, inevitably to separate the population into two mutually exclusive segments, those below the threshold and those above it, ignoring the fact that there is a large share of the highly vulnerable population that remains just above its limits (see Figure 2). However, the phenomenon linked to the fact that many families enter and leave the poverty line as their situations and living conditions fluctuate is poorly explored, thus widening the margins of deprivation. This requires a dynamic analysis capable of investigating vulnerability, socio-economic mobility of households and fluctuations affecting specific states of deprivation (see Figure 3 ).

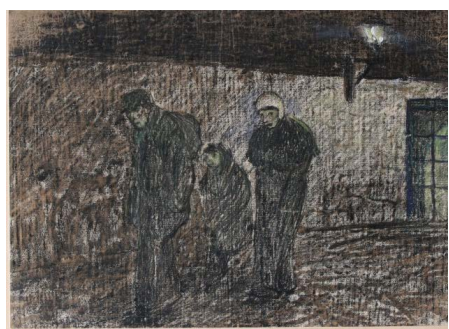

Figure 1. Lorenzo Viani (1882-1936), Poveri [Poor], 1908-1909.

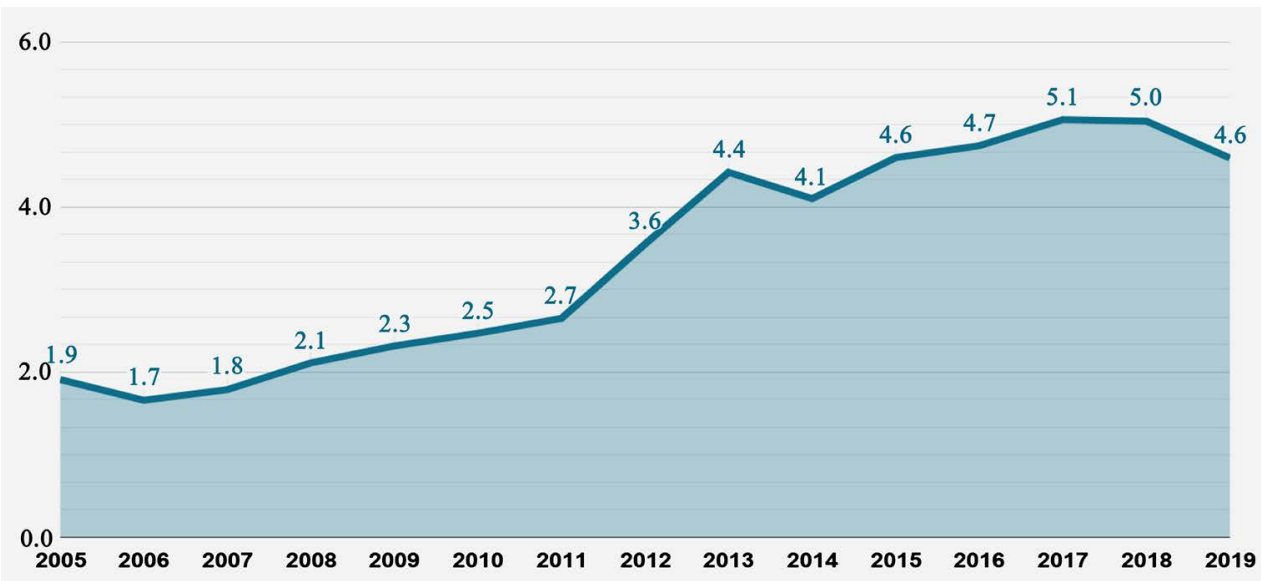

Figure 2. Absolute poverty: values in millions. Source: Istat. Data processing: "Il Redattore Sociale".

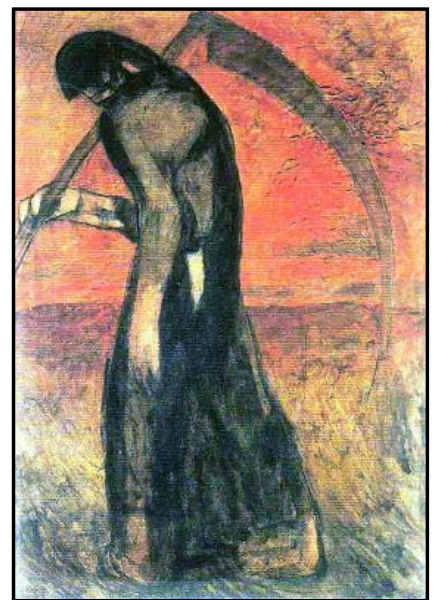

Figure 3. Lorenzo Viani (1882-1936), La guerra [War], 1917-1918. 
In Italy, poverty, in the more general sense, concerns those who do not meet a certain income threshold and live in the poverty. In this sense, we talk about poverty levels (ISTAT, 2019a) distinguishing between:

- Absolute poverty, which classifies as absolutely poor those families with a monthly expenditure equal to or below the value of the absolute poverty threshold (which differs in size and composition, family age, geographical breakdown and type of municipality of residence);

- Poverty, which treats as poor those families who have a consumption expenditure below a conventional relative poverty threshold (poverty line). Households composed of two persons who have a monthly expenditure equal to or less than this value are classified as poor. For families of different widths, the line value is obtained by applying an appropriate equivalence scale, which takes into account the economies of scale achievable as the number of components increases.

ISTAT (2019a) has produced an interesting figure representing both the standard poverty threshold and various "poverty thresholds" (corresponding to $80 \%$, $90 \%, 110 \%$ and $120 \%$ of the standard line) in order to classify families into different groups, and to show how they are distant (positively or negatively) from the standard line (Figure 4). This makes it possible to overcome simplified distinctions of poverty.

According to ISTAT estimates $(2018,2019)$, in 2018 there were more than 3 million families in relative poverty, for a total of almost 9 million (15\% of the entire population). Compared to 2017, the phenomenon worsened in 2018 in the North (from $5.9 \%$ to $6.6 \%$ ), particularly in the North-East, where the incidence increased from $5.5 \%$ to $6.6 \%$. The "Mezzogiorno", on the other hand, had an opposite dynamic $(24.7 \%$ in $2017,22.1 \%$ in 2018$)$, with a reduction in the incidence both in the South (from $24.1 \%$ to $22.3 \%$ ) both in the Islands (from $25.9 \%$ to $21.6 \%$ ). Overall, these figures showed that more than 4.6 million people in Italy lived below the poverty line and almost 1.7 million families were in absolute poverty with an incidence of $6.4 \%$ (7.0\% in 2018), for a total number of almost 4.6 million individuals (7.7\% of the total, $8.4 \%$ in 2018 ).

ISTAT poverty statistics 2019 show that absolute poverty is concentrated overall in metropolitan areas of the "Mezzogiorno" and the Centre (4.5\%) and that $8.6 \%$ of poor households are in the "Mezzogiorno", while the North appears

\begin{tabular}{|c|c|c|c|}
\hline \multirow{3}{*}{ Non povere (88.2) } & \multicolumn{2}{|c|}{ Sicuramente non povere $(80.8)$} & Linea al $120 \%(+20 \%)$ di quella standard \\
\hline & \multirow{2}{*}{ Quasi povere(7.5) } & 4.0 & Linea al $110 \%(+10 \%)$ di quella standard \\
\hline & & 3.5 & Linea standard \\
\hline \multirow[b]{2}{*}{ Povere (11.8) } & \multirow{2}{*}{ Appena povere (5.5) } & 3.1 & Linea al $90 \%(-10 \%)$ di quella standard \\
\hline & & 2.4 & Linea all' $80 \%(-20 \%)$ di quella standard \\
\hline
\end{tabular}

Figure 4. Poor and non-poor families based on different poverty lines. Year 2019, percentage values. Source: ISTAT (2019a). ISTAT's poverty statistics. Year 2019. 
to be substantially more stable $(5.8 \%)$. With regard to children living in absolute poverty (Figure 5), the figure suffered a slight decrease in 2019 (11.4\%)-with 1 million 137 thousand-compared to 2018 (12.5\%), i.e. about one child in ten. A slight recovery, compared to the past, can be noted mainly in Central Italy where the incidence of absolute poverty among minors goes from $10.1 \%$ in 2018 to $7.2 \%$ in 2019.

In the South there is an increase from $15.7 \%$ in 2018 to $14.8 \%$ in 2019 . The decline in the North remains smaller, however, with $11.2 \%$ in 2018 falling to $10.7 \%$ in 2019 . The decrease in absolute poverty is largely due to the improvement, in 2019, of the spending levels of the poorest families. The positive trend occurred in conjunction with the introduction of the "Reddito di Cittadinanza", which replaced the "Reddito di Inclusione" and affected, in the second half of 2019, over one million families in difficulty. Families with children in absolute poverty turn out to be over 619 thousand in 2019, with an incidence of $9.7 \%$, meaning by incidence of poverty the ratio between the number of families with average monthly expenditure on consumption equal to or below the poverty line and the total number of resident families. The age-disaggregated data show that the greatest criticality is observed in families with minors, where poverty is accentuated in terms of intensity, with a value of $23.0 \%$ compared to $20.3 \%$ of the general figure. Families with minors, in addition to being poorer, also experience more marked conditions of discomfort, as well as foreign ones. The under-18s affected by the phenomenon were one million and 208 thousand (12.1\%) in 2017 and one million and 260 thousand (12.6\%) in 2018 (Figure 6).

It is interesting to note that the territorial distribution of poverty is not homogeneous. In fact, $5.7 \%$ of the population lived in 2018 in the North in absolute poverty, while in the South the number reached $8.6 \%$. Considering the composition of the families, the larger ones appear to be most affected, so much so that $16.4 \%$ of them with 5 or more people live in absolute poverty. Similarly, families made up of foreigners also suffer from this condition (12.9\% of mixed families and $23.4 \%$ of foreign households). Moreover, while in the North this phenomenon

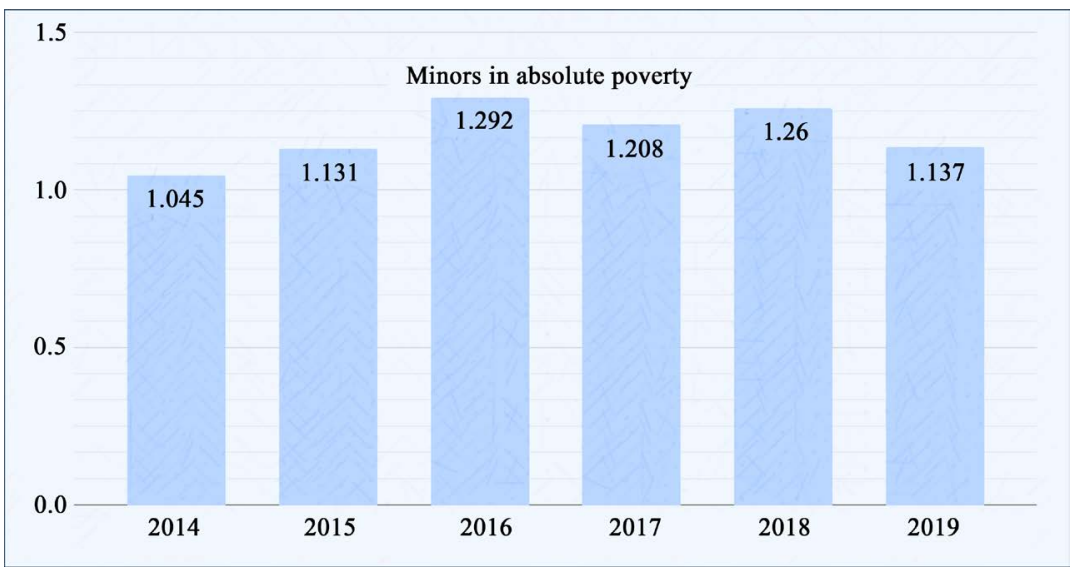

Figure 5. Minors in absolute poverty in Italy. Source Istat. Data processing: "Il Redattore Sociale", 16 June 2020. 


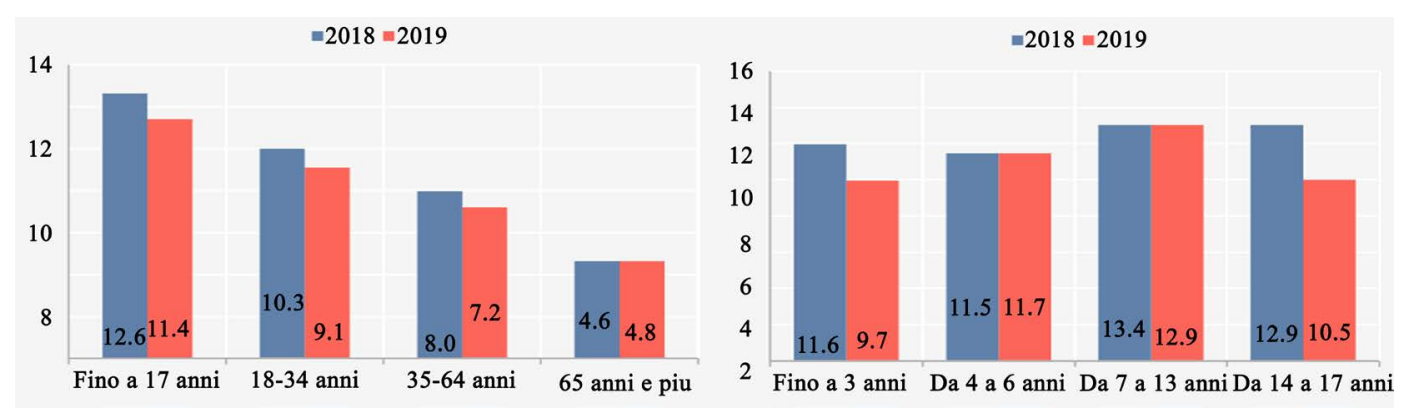

Figure 6. Incidence of absolute poverty among all individuals by age group and among children alone by age group. Years 2018-2019, percentage values

tends to be more concentrated in metropolitan areas, in the South absolute poverty is higher in small districts. ISTAT points out that these data testify to the emergence of two different dimensions within the more general phenomenon of absolute poverty: a rural one linked to the South and a more common urban one in the North.

According to the ISTAT (2020) report, spaces in the home and availability of computers for children and young people 2018-2019 in Italy $42 \%$ of students live in overcrowded houses, therefore without adequate spaces for study. To this is added the substantial number, $12.3 \%$ of 6 - 17 year old, who, in 2019, lived in homes without devices such as computers or tablets (850 thousand in absolute terms), a percentage that reaches almost 20\% in the "Mezzogiorno" confirming how central and significant the figure related to the digital divide is and how closely this is linked to spirals and re-orders of social inequalities. In addition, just over half of those with technological equipment still have to share it with other family members for both study and work needs. As if it were not enough, distance learning requires teachers and students to have adequate mastery of digital skills, which are still too low precisely in those who come from low social strata $30.2 \%$ of children engaged in distance learning have high digital skills, while two thirds possess them at elementary or basic level, while $3 \%$ none).

Another significant fact that emerges from the ISTAT report concerns the habit of reading which could be understood, in terms of the current discourse, as a real factor in the prevention of educational risk, especially necessary in situations where emergency situations are faced. Here too there are decisive shortcomings: in the years 2018-2019 52.1\% of children and young people between 6 and 17 years old have read in the last year at least one book in their spare time (about 3 million 600 thousand). Among young readers, 46.9\% read up to 3 books (weak readers), $40.7 \%$ from 4 to 11 books (average readers) and $12.5 \% 12$ or more books (strong readers). It is mainly the girls who claim to have read at least one book in their spare time. Here, too, there is a strong association between family cultural capital and the habit of reading children and strong territorial differences, with more than $60.0 \%$ of children and $6-17$ year-olds living in the North reporting to read books, in the South the share stands at $39.4 \%$. 


\section{Poverty and Education}

Education plays a central role in the training of individuals by ensuring that they have the necessary knowledge tools to live and the skills they need to enter the world of work, the capabilities providing them with the skills to engage in lifelong learning experiences. In fact, absolute poverty tends to decrease as people age and their degree increases. The level of education is substantial a key factor which appears substantial in enabling to grow up individual to grow and participate in the labour market, so much so that the choices concerning the level of education and employment are capable of influencing not only future career choices and job stability, but also the types of relationships and influences to which the individual will be exposed.

The Millennium Development Goals assume that the completion of primary education, together with achieving the other objectives, will help achieve the goal of reducing the number of people living in poverty in the world by half by 2015 , not only because education strengthens people's cultural and social profiles and helps reduce inequalities, but also because it helps high levels of education prevent countries from becoming trapped in economic stagnation and low growth. Human capital literature indicates that high-quality education at primary level generates higher returns at all subsequent levels. Human capital theory states that education creates skills that facilitate higher levels of productivity among those who possess them than those who do not (Schutz, 1961). Early investment in cognitive abilities does not produce a high return and reduces the cost of subsequent educational investment, making learning at later ages more efficient. Therefore, investing in quality early childhood learning is essential as well as increasing completion rates. Education acts as a driving force for building the knowledge, skills, attitudes and values needed to bring about significant changes in the behaviour of children, young people and adults.

The 1990 Jomtien Declaration on Education for All states that basic learning needs are not only alphabetical, but also related to the knowledge, skills, attitudes and values necessary to live and work with dignity and to participate in development. Every child learns writes UNICEF in the 2019-2030 education strategy, connecting to the sustainable development goals, which are interdependent and achieving SDG4-Ensuring inclusive and equitable education for all by 2030-will have transformative effects on others targets. SDG4 embraces a spectrum of educational levels, from kindergarten to adult education, in terms of learning outcomes, skills acquisition and equity in both development and emergency contexts. UNICEF supports the importance of child-friendly, high-quality basic education for all, in line with the 2030 Agenda for Global Education. To meet a 'framework of action' for education 2030 and SDG4, it has published its education strategy 2019-2030, which outlines three distinct objectives:

1) Equal access to learning opportunities;

2) Improvement of learning and skills for all;

3) Improvement of learning and protection for children in emergency situa- 
tions and in fragile contexts.

The satisfaction of these needs implies a responsibility to promote social justice, acceptance of differences and equality. Recent evidence suggests that the earlier investments are made in childhood to develop cognitive and social skills, the better the long-term impacts on skills and labour market outcomes will be. The evidence also suggests that the efficiency of education a quat this level should be further improved by parallel investment in children's health. It is therefore urgent to improve the quality and efficiency of basic education, both in developing and in transition countries. This also requires greater efficiency of educational expenditure, so that the development of basic skills does not take eight or more years to complete, progressive cultural adaptations of the curriculum of basic education and those of lower and upper secondary school to develop skills increasingly in demand in the global labour market, i.e. critical, reflexive and problem solving, behavioural and attitude-oriented skills, as well as digital skills related to information and relationship and communication technologies. Although a number of studies indicate that the acquisition of alphabetical skills in developing countries has a high cost in so-called "developed" countries, difficulties of a different nature are observed. In fact, the direct and indirect costs of developing these basic skills are not commonly estimated in the literature. According to the standards defined by UNESCO (2020), such basic skills should be fully mastered by the end of the primary school cycle, that is, in the five years of primary school. Overall, relevant education and skills remain the main determinants of good labour market performance for individuals.

One of the biggest concerns about poverty, especially child poverty, is the influence it could have on the acquisition of skills that are fundamental to life.

This acquisition of basic skills in children largely depends on individual endowments and investments (Cunha \& Heckman, 2008). Investments at different levels can be said to be public (school, kindergarten, social workers, public transfers) or private. In 2018, $12.6 \%$ of adolescents and children in Italy (i.e. about one million and 260 thousand) lived in absolute poverty, given this is reflected in the below percentages related to the marked differences between North and South in reference to some summary parameters concerning the poor basic skills of 15-year-olds.

In 2018, Italy scored below the OECD average in reading and science, while in mathematics it was more or less in line with the OECD average. Italy's average performance declined, after 2012, in reading and science, while it remained almost stable in mathematics (see Figure 7). Performance in reading appears to have decreased among girls while it seems to remain stable among boys, while performance in science appears to have decreased more markedly among the highest performing students, to an equivalent extent in both boys and girls. Overall, over the past six years, there has been a complete deterioration in skills, which has led to a reversal of the trend from the early 2000s to 2012. This phenomenon is accompanied by a spy of school failure (Benvenuto, 2011; Nuzzaci \& Marcozzi, 2019, 2020) 


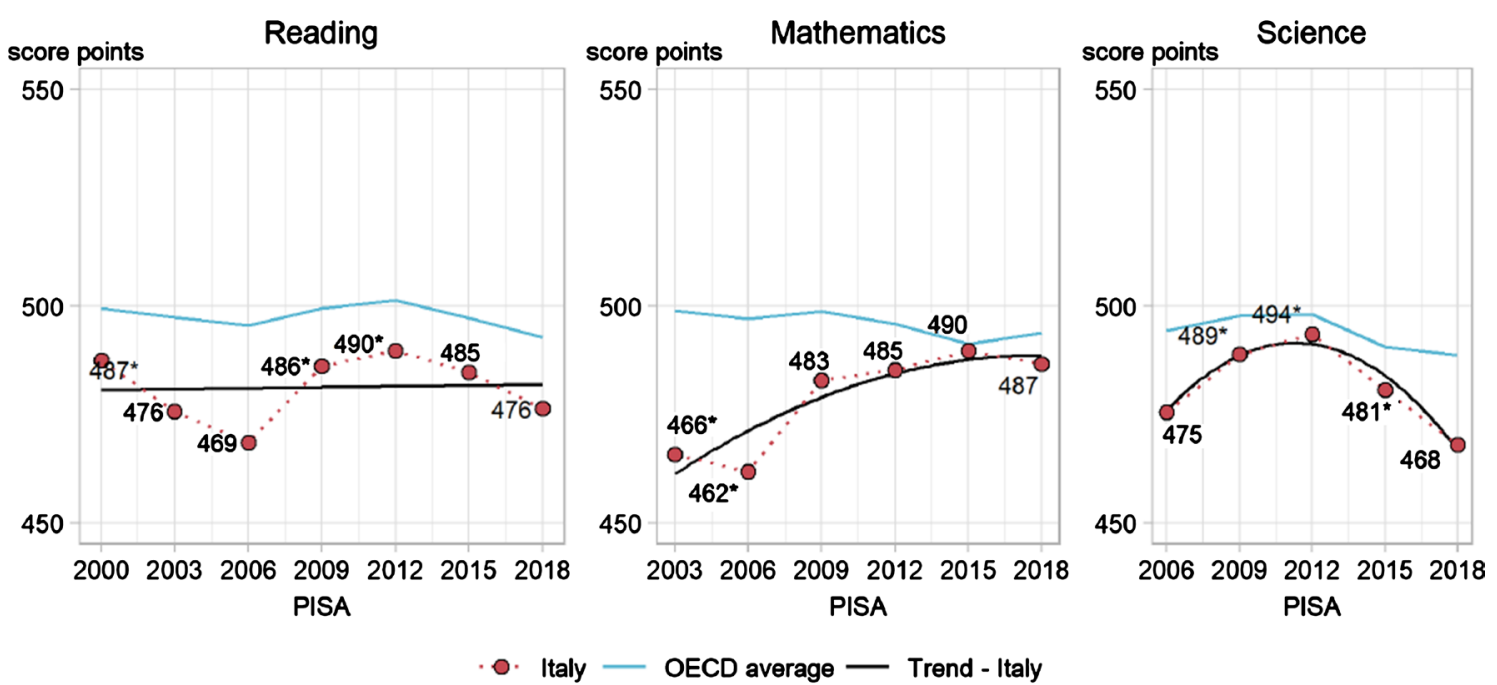

Figure 7. Distribution of skills in mathematics, science and reading on the national territory (OECD-PISA data processing)

concerning dropouts, which, in Italy, in the decade 2008-2017 stand at around $14 \%$ in the share of young people between 18 and 24 years, with a "noon" that continues to lagbehind (see Table 1). This testifies to the link between poverty and many other factors, such as school dropout (Figure 8).

\section{The Social Reproduction of Inequalities in Italy}

Education "is both the seed and the flower of economic development" (Harbison \& Myers, 1965: p. 11) and an instrument capable of breaking the intergenerational levels of poverty, which are emblematically summarized in the work of the Italian Lorenzo Viani entitled "Family of the poor" (Figure 9) and in the other images by the same author shown in this contribution (Figure 10, Figure 11). It is difficult to separate the causal effect of education from the demand for positive income. There is convincing evidence that population education levels are strongly correlated with those of economic development, but the causal effect of this relationship remains an open question, as it has not yet been clarified whether the quality of education is the cause of economic growth, or whether, conversely, income growth generates the expansion of education.

Economic inequality relates to many forms of inequality, including gender inequality, where women are at the bottom of the economic pyramid, more likely to do low-paid, precarious and underpaid work (Addati et al., 2018).

What we see is that, from a capital point of view, these disparities highlight a phenomenon in which high and growing inequalities jeopardise progress in the fight against poverty, undermining cohesion and social mobility at its root, fuelling a deep sense of injustice and insecurity in the population and urging populist or extremist "advanced".

In this interpretative framework of poverty, "vulnerability", especially economic vulnerability, has wide-ranging ramifications affecting people at different levels, who face the risk of economic, social and cultural exclusion precisely 
Table 1. Young people between the age of 18 and 24 leaving school early (percentage values). Source: Data extracted on 12 Sep 2020, 08h39 UTC (GMT) from ISTAT.

\begin{tabular}{|c|c|c|c|}
\hline \multicolumn{4}{|c|}{ Dataset: Young people aged 18 to 24 leaving school prematurely } \\
\hline Data type & \multicolumn{3}{|c|}{ (percentage values) } \\
\hline Citizenship & \multicolumn{3}{|c|}{ Total } \\
\hline Period & \multicolumn{3}{|c|}{2019} \\
\hline Sex & Males & Females & Total \\
\hline \multicolumn{4}{|l|}{ Territory } \\
\hline Italy & 15.4 & 11.5 & 13.5 \\
\hline North & 11.9 & 9 & 10.5 \\
\hline Northwest & 12.4 & 9.8 & 11.2 \\
\hline Piedmont & 11.3 & 10.3 & 10.8 \\
\hline Aosta Valley/Vallée d'Aoste & 18.5 & 9.7 & 14.3 \\
\hline Liguria & 13.1 & 6.6 & 10.1 \\
\hline Lombardy & 12.8 & 10.1 & 11.5 \\
\hline Northeast & 11.1 & 8 & 9.6 \\
\hline Trentino Alto Adige & 10.7 & 7.8 & 9.3 \\
\hline Bolzano/Bozen & 14 & 9.1 & 11.6 \\
\hline Trento & 7.1 & 6.4 & 6.8 \\
\hline Veneto & 9.2 & 7.6 & 8.4 \\
\hline Friuli-Venezia Giulia & 9.7 & 7.4 & 8.6 \\
\hline Emilia-Romagna, Italy & 13.9 & 8.5 & 11.3 \\
\hline Center & 12.7 & 8.9 & 10.9 \\
\hline Tuscany & 12.3 & 8.2 & 10.4 \\
\hline Umbria & 10.5 & 8.4 & 9.5 \\
\hline Brands & 11.6 & 5.6 & 8.7 \\
\hline Lazio & 13.6 & 10.2 & 12 \\
\hline Noon & 20.7 & 15.5 & 18.2 \\
\hline Abruzzo & 15 & 4.2 & 9.8 \\
\hline Molise & 14.5 & 7 & 11 \\
\hline Campania & 18.8 & 15.7 & 17.3 \\
\hline Puglia & 21.1 & 14.4 & 17.9 \\
\hline Basilicata & 14.6 & 8.6 & 11.8 \\
\hline Calabria & 21.2 & 16.6 & 19 \\
\hline Sicily & 24.5 & 20.1 & 22.4 \\
\hline Sardinia & 21.9 & 13.1 & 17.8 \\
\hline
\end{tabular}




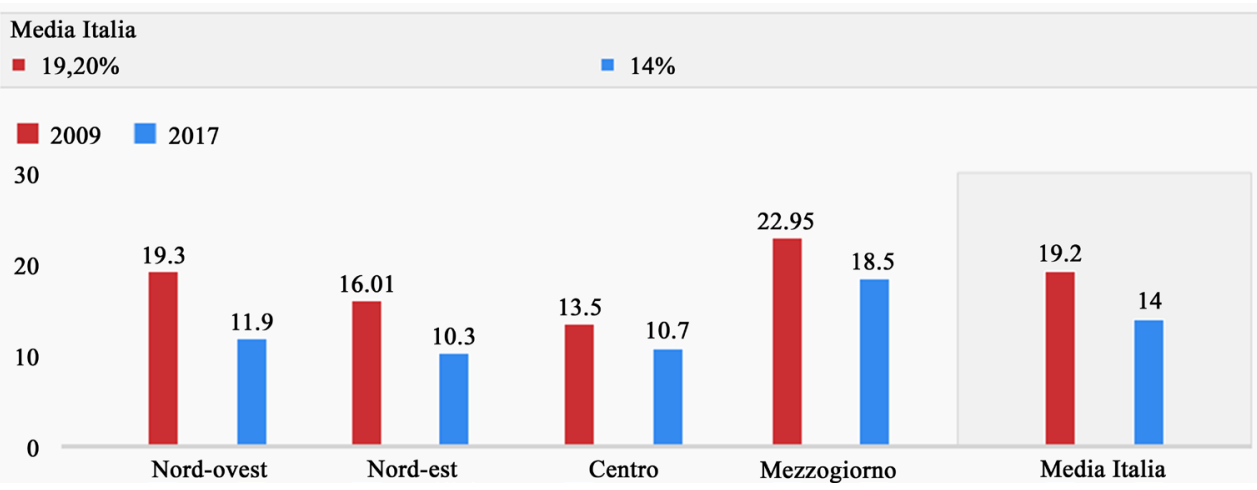

Figure 8. Distribution of the phenomenon of school dispersion on the Italian territory-comparison between 2009 and 2017. Source: Openpolis (2019)

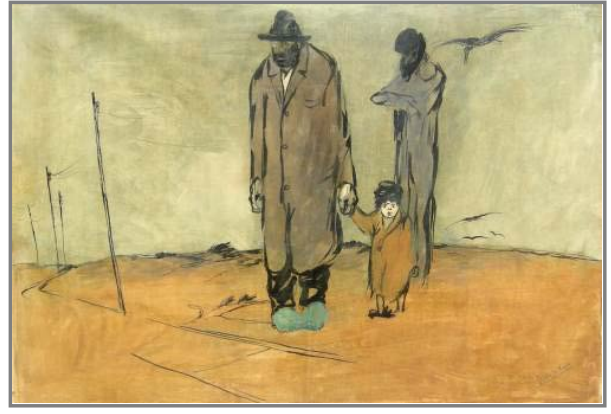

Figure 9. Lorenzo Viani (1882-1936), Famiglia di poveri [Family of the poor], 1907-1908.

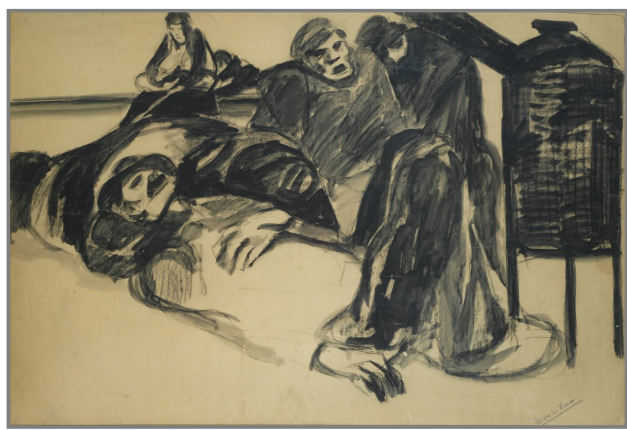

Figure 10. Lorenzo Viani (1882-1936), Poveri di Parigi [Poor of Paris], 1908-1909.

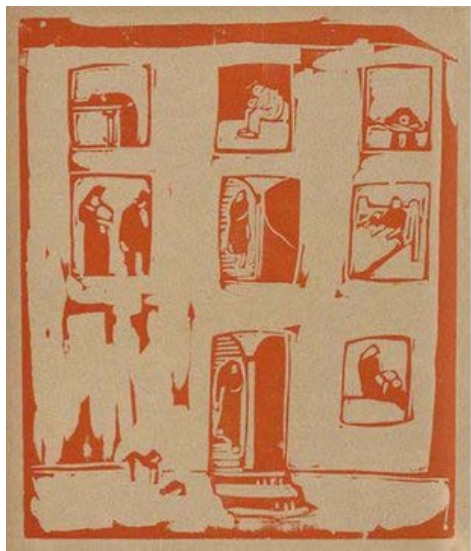

Figure 11. Lorenzo Viani (1882-1936), La casa dei poveri [The house of the poor], 1915-1916. 
because of poverty. This also explains how this form of exclusion creates isolation and loss of support network connections and institutional exclusion mainly from institutions in the educational and health social sectors (Cutter, Boruff, \& Shirley, 2003) (see Figure 11). Thus, the reciprocal effects of different forms of exclusion increase their vulnerability (Böhnke, 2015) and the elimination of social exclusion and extreme deprivation requires policies that ensure the realisation of civil rights and reconstruct markets. But once again the problem is mainly one of basic education. In fact, education remains a powerful predictive factor in the life chances of adults and those who leave school with little or no education have access to fewer opportunities in future life (Alivernini, Manganelli, \& Lucidi, 2017), establishing itself as a tool for freeing themselves from the original social and cultural conditions.

From this of perspective, Amartya Sen's contribution goes beyond the traditional conception of development as economic growth by attributing it to the extension of people's freedoms and opportunities (capability), so that everyone can have the right to live an existence to which they attach value. In addition to the parameter traditionally used to measure poverty, i.e. the possession of sufficient resources to lead a dignified life, Sen considers other aspects of human life that allow development, such as a good level of education, health, active participation in community life, freedoms and fundamental human rights. It is precisely with these studies that the concept of multidimensionality of development and the centrality of people, within the social group to which they belong, considered protagonists of this process, and active agents of their change, comes into play.

The concepts of development and well-being, beyond the simple possession of goods, are in the capability approach closely related to the expansion of the capabilities and means available (Sen, 1987, 1994, 2000, 2010a, 2010b).

In some countries, including Italy, the poor tend to remain poor and the rich always rich, as socio-economic conditions are handed down from generation to generation and young people now have to deal with a deeply unequal market (13\% of Italian under-29s are in working poverty), characterized, in the face of the recovery in employment levels after the 2008 crisis, by the increase in job insecurity and the vulnerability of more stable jobs. It remains clear from the various national and international reports that education and employment levels play a substantial protective role against poverty and that, once again, the spread of poverty decreases as the degree increases, with an incidence of $3.4 \%$ for those who have obtained at least the upper secondary school diploma with $8.6 \%$ or at most the secondary school license ( $9.8 \%$ in 2018). Associated with the degree are the condition and professional position. In the Italian context, $62.2 \%$ of people between the age of 25 and 64 have at least a diploma, while in the EU this percentage is higher $(78.7 \%)$. The share of the population with tertiary qualifications also continues to be very low (19.6\% as against $33.2 \%$ in the EU). In the "Mezzogiorno", both levels of education (54\% have at least one diploma, 65.7\% 
in the North) and employment rates remain lower, also with regard to the most educated individuals ( $71.2 \%$ among graduates, $86.4 \%$ in the North) with a territorial gap that appears very wide in relation to graduate employment rates reaching 24.9 points (ISTAT, 2019a).

In 2019, research by the Openpolis Foundation shows that Italy is at the lowest levels of female employment in the European Union and as/like, compared to an average of 66.5 employed per 100 women between 20 and 64 years, hi is in the penultimate place with $52.5 \%$, just above Greece (48\%). This gap increases if you compare only men and women with children. Moreover, with a European average of 18.8 percentage points difference between fathers and mothers in employment, Italy is almost 10 percentage points above (28.1). To read these data, much research relates women's employment, which is directly linked to working conditions and the reconciliation of family and profession, with the availability of educational services, such as crèches. However, the proportion of childless women aged between 20 and $49(62.4 \%)$ is also lower than the European average (77.2\%), with, according to ISTAT, 625,000 housewives aged between 15 and 34 in Italy declaring that they are mainly engaged in household chores, that they do not have a job and are not unemployed.

It is an overall picture that shows weaknesses that we could call "systemic" and ranging from problems related to education to those of the transition from school to the world of work, from the disconnect between the supply and demand of skilled work to the absence of prospects, forcing many young graduates to leave Italy in search of more qualified jobs. The situation is aggravated when many young Italians are in an undefined and vulnerable position, that is, they do not study, they do not work and if they do their income is minimal.

\section{Educational Poverty in the Age of COVID-19}

In the event of natural disasters, pandemics, conflicts or other major problems, which make the economy and territories weaker, forms of poverty are increasing, helping to prolong or worsen the pre-existing conditions of those sections of the population that were already close to the poverty line.

The situations that we could define as "at risk" collide with events related to events that can aggravate and/or give rise to new difficulties such as the situation in which the world finds itself at this time of COVID 19 pandemic. In this state of emergency, crossed by poverty, the share of Italians' wealth is reduced, widening the gap that sees the richest $1 \%$ of Italians, in 2019 , exceed what belonged to the $70 \%$ poorest, from the point of view of wealth. to Following the pandemic, in a country like Italy, governed by large disparities in income distribution, with an average income figure below the EU average (72 \$ per day) and that of the USA (111 \$ per day), the data today appear even more depressing,

The data collected so far by Save the Children take into account different indicators such as early school drop-out rates, skills outcomes in OECD PISA school education and the educational and cultural context offered by the territo- 
ry, where children participate in recreational, sports, extracurricular cultural activities. The analysis highlights both the relationship between family poverty and educational poverty, and the intergenerational transmission of socio-economic and cultural disadvantage, which continues to act unconditionally. This examination is supported by the relationship between family condition and learning, which sees, compared to the worsening of the first, the results of the second in all subjects in the tests, confirming the close relationship between school performance and the socio-economic-cultural status of the family in primary school (2018/2019).

Educational poverty in any case is not only linked to the school context, but also to everything related to "deprivation" and the possibility for children and adolescents to grow through culture, sport, reading, educational experiences offered by the world of non-school, all these deprivations that could have harmful effects on the weak population and aggravate the conditions of educational poverty. ISTAT's Aspects of Daily Life survey provides an overview of such experiences ranging, for example, from participation in musical concerts to the use of theatrical or cinematographic performances, from visiting museums, archaeological sites or monuments to the practice of sports, from reading books to participating in cultural events of various kinds.

In the light of what has been said, it is clear that the COVID19 pandemic, which has caused the condition of the so-called lockdown and in particular the closure of schools and universities all over the world and in Italy, with very devastating impacts on the lives of children, adolescents and their families, has had the effect of exponentially increasing economic poverty and consequently educational poverty, which can be interpreted as two sides of the same coin. In this sense Save the Children (2020) highlights the serious impact that COVID-19 is having producing on the lives of children, adolescents and their families, with the risk of drastically increasing economic and educational poverty. The increase in unemployment, estimated by the International Monetary Fund for 2020 at $12.7 \%$, and the consequent reduction in the economic capacity of families risk significantly increasing the incidence of material poverty among children. According to research conducted by the Fondazione Studi Consulenti del Lavoro, of the approximately 9.5 million workers unable to work in March, 3.7 million live in single-income families, where the only source of income has therefore been lost. Half of these families also have dependent children. Among them are 439 thousand single parents (12\%). Looking at the latest available data of 2018 , there were about one million 260 thousand children and adolescents living in absolute poverty in Italy, 12.6\% (ISTAT, 2019b: p. 1).

If there is no adequate and immediate response at political and social level, there will be a risk of creating new forms of poverty, of marginalization, causing those who are in "barely poverty" to slip into absolute poverty, that is, those on and around the threshold. At the same time, the risk also applies to those groups considered to be "medium", which could be affected by serious economic prob- 
lems, with the consequent worsening of the and inequalities.

The alarming disparities in income distribution, especially for those who do work, including from a capital point of view, highlight a phenomenon in which high and growing inequalities accumulate exponentially, jeopardising progress in the fight against poverty, undermining cohesion and social mobility, fuelling a deep sense of injustice and insecurity in the population and urging populist or extremist "advanced". So to the audience of precarious and unstable workers hard hit by the consequences of the restrictions, to employees who could not carry out their activities and those who earned less than 1250 euros per month, of which $24.2 \%$ were in 2019 below the threshold of 1000 euros, it only corresponds to the risk of further slippage of certain sections of the population into absolute poverty and a further group of those 2 million and 192 thousand minors today in relative poverty, which, neutralizing not only the improvements estimated for 2019 due to the introduction of citizenship income, exponentially raise the absolute poverty rate beyond $20 \%$ in a short time. This situation affects economic factors and the worsening poverty situation, which already affected a large section of the population, especially children, following the 2008 crisis and which is now in danger of spreading and affecting new social groups. In this regard, the Save the Children (2020: p. 1) Report states that the slippage of an additional group of minors in absolute poverty could now take place even faster if it is not sheltered with organic and rapid implementation measures, which must provide effective emergency social policies. The experience of the previous decade raises fears that many of the children in relative poverty who are defined as "just poor", that is, less well-off than the national average (about half of the 2 million 192 thousand minors in relative poverty estimated by ISTAT for 2018) could slip into absolute poverty and swell the already dramatically crowded set of the million 260 thousand children identified as absolute poor. Thus, absolute child poverty could rise from 12 to $15 \%-20 \%$ in a short time with an alarming "social débâcle" that would involve one of the most developed countries in the world.

The data reported by Save the Children (2020) confirm, therefore, a marked deterioration in the quality of life of families with minors caused by the economic impact on a multitude of dimensions and variables, among which it is important to highlight all the difficulties related to education and the use of distance learning that has not always been able to reach all students, despite the efforts made by educational institutions and teaching and non-teaching staff. The most obvious risk, however, was to further weaken the weakest groups and pupils in more critical conditions on the school dropout front, which in Italy has laboriously fallen to $14.5 \%$ (as of 2018), there is now a real risk that we will return to the 2008 values, above $19 \%$.

Although to a lesser extent than the total there are also cases of educational poverty due to the lack of availability of means of communication (fast internet line, fast smartphones, high-end computers able to send real time streaming 
videos) necessary and required to take the lessons and take the exams remotely. But if the problem for higher education appears to be mitigated, since it is a largely adult population, the problem can only concern the weakest groups of children, who are at risk of double exclusion.

From here it is understood how poverty undergoes radical shifts of meaning every time an adjective (absolute, relative, etc.) follows it or connects to catastrophic or pandemic events or other emergency factors. This requires thinking about it and rethinking its structure, components and indicators according to its complex and varied nature to always interpret it at its best and to fight it at its root, so that all individuals can live their lives and not only survive the human experience.

\section{Conclusion}

Over the last few years, the absolute poverty rate in Italy still shows a rather problematic situation, affecting above all children under 18. Two particularly significant data emerge. In the first place, the gap between generations has increased, even compared to the previous fifteen years. The other element is the reversal of the levels of poverty between generations. If about a decade ago it was the elderly who were most in difficulty, today, on the contrary, it is the minors under 18 who are most affected by absolute poverty. Therefore, it is currently noticeable that the share of absolutely poor individuals grows with decreasing age and the younger part of the population residing in Italy tends to be the most vulnerable. Protecting children from poverty is to be considered both a priority and a development strategy, as the development goals of the 2030 Agenda also wish.

The data presented in this article deserve further and in-depth reflection, since child poverty is a phenomenon that does not only concern economic aspects and specific age groups or groups of people, but affects the whole of society, as stated by the most advanced research. Failing to protect minors from conditions of absolute poverty and educational poverty also risks being one of the most serious mistakes that a society can make, which can lead to the impoverishment of human capital and which involves very high social costs.

The increase in educational poverty is linked to phenomena of a different nature that undermine the exercise of active citizenship of individuals and social cohesion, as they deprive the latter of the possibility of acquiring literacy tools and functionalities necessary for personal, cognitive, socio-relational development, etc. The lack of such tools prevents individuals in the future from finding stable employment and living in adequate and dignified conditions, that is, essentially, from finding themselves in situations of poverty, dependence on social assistance and risk of exclusion.

This calls into question the need for constant monitoring of the various phenomena to which educational poverty is attributable in order to be able to contrast the various emerging problems at different levels, since it is to be under- 
stood as a multifactorial dimension, an expression of the interrelation between variables social, economic and cultural.

While it is true that in recent years there have been many efforts by European and national institutions to raise public awareness of these aspects, much remains to be done in terms of cultural possibilities and the quality of educational services offered to those who are below or below the poverty line.

\section{Conflicts of Interest}

The author declares no conflicts of interest regarding the publication of this paper.

\section{References}

Addati, L., Cattaneo, U., Esquivel, V., \& Valarino, I. (2018). Care Work and Care Jobs for the Future of Decent Work. Geneva: International Labour Organization.

Alivernini, F., Manganelli, S., \& Lucidi, F. (2017). Dalla povertà educativa alla valutazione del successo scolastico: Concetti, indicatori e strumenti validati a livello nazionale. [From Educational Poverty to the Evaluation of School Success: Concepts, Indicators and Tools Validated at National Level.] ECPS Journal, 15, 21-52.

Alkire, S., \& Foster, J. (2011a). Counting and Multidimensional Poverty Measurement. Journal of Public Economics, 95, 476-487. https://doi.org/10.1016/j.jpubeco.2010.11.006

Alkire, S., \& Foster, J. (2011b). Understandings and Misunderstandings of Multidimensional Poverty Measurement. The Journal of Economic Inequality, 9, 289-314. https://doi.org/10.1007/s10888-011-9181-4

Alkire, S., \& Foster, J. (2016). Dimensional and Distributional Contributions to Multidimensional Poverty. OPHI Working Paper 100, Oxford: University of Oxford.

Benvenuto, G. (2011). La scuola disuguale [Lat Unequal School]. Rome: Anicia.

Böhnke, P. (2015). Wahrnehmung sozialer Ausgrenzung [Perception of Social Exclusion]. Aus Politik und Zeitgeschichte, 67, 18-25.

Cunha, F., \& Heckman, J. J. (2008). Formulating, Identifying and Estimating the Technology of Cognitive and Noncognitive Skill Formation. Journal of Human Resources, 43, 738-782. https://doi.org/10.1353/jhr.2008.0019

Cutter, S. L., Boruff, B. J., \& Shirley, W. L. (2003). Social Vulnerability to Environmental Hazards. Social Science Quarterly, 84, 242-261. https://doi.org/10.1111/1540-6237.8402002

Harbison, F., \& Mayers, C. (1965). Manpower and Education. New York: McGraw-Hill Book Company.

ISTAT (2019a). Le statistiche dell'ISTAT sulla povertà. Anno 2018 [Poverty Statistics. Year 2018]. Roma: Istituto Nazionale di Statistica.

https://www.istat.it/it/files/2019/06/La-povert\%C3\%A0-in-Italia-2018.pdf

ISTAT (2019b). Le statistiche dell'ISTAT sulla povertà. Anno 2019 [Poverty Statistics. Year 2019]. Roma: Istituto Nazionale di Statistica. https://www.istat.it/it/files/2020/06/REPORT POVERTA 2019.pdf

ISTAT (2020). Spazi in casa e disponibilità di computer per bambini e ragazzi [Spaces in the House and Availability of Computers for Children and Teenagers for the Years 20182019]. Rome: National Statistical Institute. 
https://www.istat.it/it/files//2020/04/Spazi-casa-disponibilita-computer-ragazzi.pdf

Nuzzaci, A., \& Marcozzi, I. (2019). Fattori di rischio scolastici e dropout nella percezione degli studenti: Il progetto internazionale ERASMUS KA2 ACCESS [School Risk Factors and Dropout in Students' Perception: The International ERASMUS KA2 ACCESS Project]. Giornale Italiano della Ricerca Educativa (Italian Journal of Educational Research), $12,48-68$.

Nuzzaci, A., \& Marcozzi, I. (2020). L'abbandono scolastico nella percezione degli studenti: un focus del progetto ACCESS [Early School Leaving in Students' Perception: Focus on the ACCESS Project]. In SIRD, SIPES, SIREM, SIEMeS, Le Società per la società: Ricerca, scenari, emergenze (Tomo 1, pp. 127-137). Atti del Convegno Internazionale SIRD Roma 26-27 Settembre 2019/Proceedings of the SIRD Rome International Conference, Roma, 26-27 September 2019, 127-137.

Nuzzaci, A., Minello, R., Di Genova, N., \& Madia, S. (2020). Povertà educativa in contesto italiano tra istruzione e disuguaglianze. Quali gli effetti della pandemia? [Educational Poverty in the Italian Context between Education and Inequalities. What Are the Effects of the Pandemic]. Lifelong, Lifewide Learning (LLL), 16, 76-92.

Ravallion, M. (1998). Poverty Lines in Theory and Practice. Living Standard. Measurement Study Working Paper 133. https://doi.org/10.1596/0-8213-4226-6

Ravallion, M., \& Bedani, B. (1994). How Robust Is a Poverty Profile? The World Bank Economic Review, 8, 75-102. https://doi.org/10.1093/wber/8.1.75

Save the Children (2020). Riscriviamo il futuro. L'impatto del coronavirus sulla povertà educativa [Let's Rewrite the Future. The Impact of the Coronavirus on Educational Poverty]. Roma: Save the Children Italia Onlus.

https://s3.savethechildren.it/public/files/uploads/pubblicazioni/limpatto-del-coronavir us-sulla-poverta-educativa $0 . p d f$

Schultz, T. W. (1961). Investment in Human Capital. American Economic Review, 51, $1-17$.

Sen, A. K. (1986). Choice, Well-Being, Equity. Bologna: The Mill.

Sen, A. K. (1987). The Standard of Living. Lecture II. Lives and Capabilities. In G. Hawthorn (Ed.), The Standard of Living (pp. 20-38). Cambridge: Cambridge University Press. https://doi.org/10.1017/CBO9780511570742

Sen, A. K. (1994). Inequality. A Critical Review (1992). Bologna: The Mill.

Sen. A. K. (2000). Development Is Freedom. Milan: Mondadori.

Sen. A. K. (2010a). The Idea of Justice (2009). Milan: Mondadori. https://doi.org/10.2307/j.ctvjnrv7n

Sen. A. K. (2010b). The Place of Capability in a Theory of Justice. In H. Brighouse, \& I. Robeyns (Eds.), Measuring Justice. Primary Goods and Capabilities (pp. 239-253). Cambridge: Cambridge University Press. https://doi.org/10.1017/CBO9780511810916.011

UNESCO (2020). Take a Survey: COVID-19 and Early Childhood Education Workforce. https://en.unesco.org/news/take-survey-covid-19-and-early-childhood-education-work force

United Nations (2015). Transforming Our World: The 2030 Agenda for Sustainable Development. New York: United Nations General Assembly. 